Jenista, (Spon. by W.J. Oliver). C.S. Mott Children's Jenista, (Spon. by W.J. Oliver). C.S. Mo
Hospital, Univ. of Michigan, Ann Arbor, MI.

506 The AAP has recommended that pediatricians take the lead in banning cigarette smoking in all pediatric health care facilities. This study investigated the use of "nonsmoking" policies and their planned revisions, problems in enforcement and challenges to restrictive or lenient policies. Mail surveys were sent to all 320 hospitals affiliated with pediatric training programs as the institutions most likely to atternpt to comply with the AAP recommendations. Based on data rom the frst $1 / 3$ of the sample, the $26 \%$ or defined areas of larger hospitals $71 \%$. All but 3 had formal smoking policies, in place for a median of 6 mos- 2 yrs. $72 \%$ had revised or were planning revision within the next year. $57 \%$ of policies were governed by city, state, university or other regulating bodies. Smoking was entirely banned from all public and private areas in $8 \%$. All programs restricted smoking to designated areas only. Most policies applied to all patients, visitors and employees and to all in- and outpatient facilities. The most common designated areas for smoking were: cafeteria $66 \%$, private of fices $62 \%$, outside courtyards $48 \%$, staff lounges $41 \%$, smoking waiting rooms $40 \% ; 78 \%$ allowed patient smoking. Policies were made public by signs $93 \%$ or brochures $55 \%$. Penalties were usually "leave nonsmoking area" $79 \%$ or disciplinary measures for employees $47 \%$ Responsibility of enforcement lay with all employees $88 \%$, security $41 \%$ or supervisors $41 \%$. Only $19 \%$ reported strict enforcement with stringent penalties. $48 \%$ of policies had been challenged by employees, patients
or physicians; all but one were dealt with by the hospital administration. or physicians; all but one were dealt with by the hospital administration.
Although nearly all policies have been recently or are being revised, pediatric hospitals and wards remain sadly remiss in controlling smoking.

INFLUENZA IN CHILDREN WITH CANCER. A Kempe, CB Ha11, NE MacDonald, HR Foye, ED Lewis, HJ Cohen, $B$ Luke, 507 C Bulberg. U. of Rochester, Strong Mem. Hosp., Dept. Hosp.of Eastern Ontario, Ottawa, Ontario.

Although annual influenza(flu) vaccination is recommended for patients(pts) in designated high-risk categories, little data exist to support these recommendations in pediatric pts. We prospectively followed a group of oncology pts (OP) on pts. We prospectively followed a group of oncology pts (OP) on
chemRx or off $R x$ for $<1$ yr. who were not immunized against flu chemRx or off $\mathrm{Rx}$ for $<1$ yr. who were not immunized against flu
during 2 flu seasons to determine their relative risk of infecduring 2 flu seasons to determine their relative risk of infec-
tion and complications compared with matched sibling control (SC) and community control(CC) groups. Results of culture \& serology data (episodes/patient seasons) show a higher occurrence of flu in the OP group (33\%) than in the $\mathrm{SC}(22 \%)$ or the $\mathrm{CC}$ groups

$(14 \% \mathrm{p}=.01 \mathrm{chi}-\mathrm{sq})$. A "protective" preseason titer of $\geq 1: 32$ did not prevent flu in $20 \%$ of the OP group compared with $4 \%$ of the SC and $2 \%$ of the $\mathrm{CC}$ groups $(\mathrm{p} .02)$. No significant differences were noted in duration of reported symptoms between groups and clinical complications occurred too infrequently to analyze. $2 / 18(11 \%)$ of the culture $\oplus$ OP group were hospitalized during their illness and an additional $1 / 18$ had a nosocomial infection. None of the control children were hospitalized. We conclude that OP's are at greater risk of acquiring flu than are normal children. The duration of their symptoms appears similar to that in normal children but hospitalization may accompany infection more frequently. A preseason titer of $\geq 1: 32$, of ten used as a marker of successful immunization in flu vaccine trials, was poorly protective in the $O P$ group but was protective in controls. Our findings have significant implications for vaccination recommendations and suggest the need for a clinical efficacy trial of the flu vaccine.

MOTHER'S BIRTH WEIGHT AND THE RISK OF PRETERM AND +508 SMALL FOR GESTATIONAL AGE BIRTH Mark A. Klebanoff

† 508 (NICHD, NIH, Bethesda, MD) (Spon. by J.L. Mills) Birth certificates for Temnessee births during
1979-1984 were linked with their mothers' birth 1979-1984 were linked with their mothers' ' birth
certificates for births in Tennessee during 19591966 ( $n=33,108$ white; 10,783 black). Maternal birth weight was positively correlated ( $p<0.0001$ ) with both mean infant birth weight and the fraction of offspring $<2500$ and $<1500 \mathrm{~g}$. Examining the relationship between maternal birth weight and either intrauterine growth or duration of gestation showed that the rate of
small for gestational age (SGA) varied from a low of $5.9 \%$ for small for gestational age (SGA) varied from a low of $5.9 \%$ for
white and $4.8 \%$ for black mothers weighing $4000-4499 \mathrm{~g}$ at birth to a maximum of $20 \%$ for low birth wt mothers of either race. In contrast, the rate of preterm birth varied little by matemal birth weight for both whites and blacks. The race-adjusted odds ratios and $95 \%$ C.I. are in the figure. These data suggest that maternal birth weight exerts a stronger inmaternal birth weight exerts a stronger
fluence on IUGR than on the duration of gestation. Women who were smaller than average at birth may be as much as 4 times more likely to give birth to a SGA infant than are women who were larger than average at birth. Women who were large at birth are at low risk for the delivery of a SGA infant.

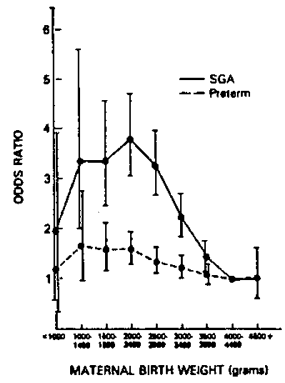

THE EFFECTS OF POLYBROMINATED BIPHENYLS (PBB) ON THE HUMAN CYTOCHROME P-450 SYSTEM (P-450).

509 George H. Lambert, Harold Humphrey, and Dale School of Med. Dept Cotlietta), Loyola U., Stritch Dept, of Public Center, University of Chicago, Chicago, IL. Humans have been exposed to many polyhalogenated biphenyls Including PBB. The effects of PBB exposure on P-450 may be the most sensitive indicator of biologic effect and has never been studied in man. We examined the effects of PBB on P-450 as determined by the caffeine breath test (CBT) in healthy nonsmoking adults from rural Michigan with $(+)$ and without $(-)$ detectable PBB serum levels and prepubescent children w1th known perinatal exposure to $\mathrm{PBB}$. The results were compared to the $\mathrm{CBT}$ results previously obtalned from nonexposed urban adult nonsmokers and age-matched children.

$\begin{array}{lccccc}\text { rura1 adults } & \text { N } & \text { CBT }( \pm \text { SEM }) & \text { rural ch11dren } & & \text { N } \\ \quad \text { + PBB levels } & 43 & 5.6 \pm .3 & \text { + PBB exp. } & 41 & 6.8 \pm .5 \\ \text { - PBB leve1s } & 12 & 5.4 \pm .6 & \text { urban ch1ldren } & & \\ \text { urban adults } & 29 & 4.0 \pm .3 & \text { - PBB exp. } & 23 & 7.0 \pm .4\end{array}$

The nonexp. and $\mathrm{PBB}$ exp. children had similar CBT data. The adult groups were not significantly different from each other except for the rural adults $+P B B$ levels who had significantly higher $\mathrm{CBT}$ values than the nonexposed urban adults (P<.01). Future studies are needed to determine if there is a difference in $\mathrm{P}-450$ function as determined by the CBT between the rural and urban adult populations who are nonexposed to PBB or exposed with non-
detectable PBB serum levels, or exposed in the perinatal pertod.

MOLECULAR EPIDEMIOLOGY OF PSEUDOMONAS CEPACTA (PC) IN PATIENTS WITH CYSTIC FIBROSIS (CF). John J. LAP IMa,

$510 \frac{\text { Daniel V. Schldlow, Thomas D. Edlind, Joel Mortensen, }}{\text { Terrence L. Stu11 (spon. by C. Wilson), Medical College }}$ of Pennsylvanla, Depts. of Pediatrics, Mi crobiology/ Immunology and Temple U. Sch. of Med., St. Christopher's Hospital for Children, Dept. of Pediatrics, Philadelphia. PC is now recognized as an important pathogen among CF patients. However, little is known regarding its epidemiology. We have developed a typing system which allows determination of iso1 ate genotype. Following isolation and endonucl ease digestion, PC chromosomal DNA fragments were separated by agarose gel electrophoresis, transferred to nitrocellulose, and probed with $32 \mathrm{p}$ labelled ribosomal RNA purified from Escherichia coli. Hybridization band polymorphism allowed discrimination of unique and identical isolate genotypes. Analysis of $9 \mathrm{PC}$ isolates of un known epidemiological significance ob tained from 6 geographically diverse locations revealed 8 distinct genotypes. The 2 identica 1 isolates originated from the same CF center. Of $7 \mathrm{blindly}$ selected (nonsibling) PC isolates obtained from our CF center, 3 were found to have an 1dentic al genotype. Twelve PC isolates obtained from the 8 members of 3 sibships attending our CF center were available for study. In 2 of these 3 familles, the isolates from each sibling exhlbited Identical genotype. In the remaining $f$ am: ly each of the 3 siblings were colonized by genotypically distinct. strains, although siblings A\&B had identical isolates at certain times. Our data suggest that individuals attending the same CF center may be colonized with conmon PC strains. Furthermore, we have shown that while some siblings with $C F$ are colonized with identical PC s trains, others are not. The epidemiologic relevance
of our findings in siblings requires further elucidation.

\section{ARTERIOSUS ARTERIOSUS}

LOWER SOCIOECONOMIC GROUPS HAVE A HIGHER M.M. Mas C.E. Mullins, J.T. Bricker, D.G. McNamara.

It has been suggested anecdotally that socioeconomic differences exist between patients (pts) with different diagnostic eategories of congenital cardiac defects. The purpose of this study was to evaluate socioeconomic status (SES) in a retrospective manner in populations presenting with two common congenital cardiac defects: isolated patency of the ductus arteriosus (PDA), excluding newborns and prematures and isolated atrial septal defect (ASD). All pts presenting with the diggnosis of ASD or PDA over a 5 year period were included. Pts with associated cardiovascular malformations or noncardiovascular syndroines were excluded. 101 children with PDA and 59 with ASD were included. Low SES was identified by information for eligibility for county, state, or federal economic assistance and classified according to the federal guidelines for the poverty level. Patients were placed into racial and ethnic categories based on information given at the time of the first clinic visit. Results of this assessment were that $37 \%(37 / 101)$ of PDA and $15 \%(9 / 59)$ of ASD pts were in the low SES eategory. Racial/ethnic distribution among PDA's was 54/101 Anglo, 10/101 black, 33/101 hispanic, 4/101 Asian. Distribution among ASD's was 43/59 Anglo, 4/59 black, 7/59 hispanic, 5/59 Asians. Significant differences were found between the ASD and PDA groups for SES $\left(\mathrm{X}^{2}\right)$, and between proportions of Anglo and hispanic pts. Based on this we conclude that a difference in SES exists between ASD and PDA pts. Possible explanations are: differences in perinatal care or nutrition, differences in hereditary risk based on genetic background, and bias in referral. 